\title{
PEMBESARAN LARVA KERAPU TIKUS (Cromileptes altivelis) DENGAN TINGKAT FOTOPERIOD YANG BERBEDA
}

\author{
Jhon H. Hutapea*), Wardoyo*) dan Ketut Maha Setiawati*)
}

\begin{abstract}
ABSTRAK
Perbenihan kerapu tikus. Cromileptes altivelis belum mencapai tingkat keberhasilan yang menuaskan, disebabkan oleh terbatasnya informasi tentang aspek biologi dan lingkungan larva kerapu yung tersedia. Untuk itu perlu dilakukan berbagai penelitian tentang aspek tersebut, seperti pengaruh lama penyinaran terhadap pertumbuhan dan sintasan larva kerapu tikus. Penelitian ini dilaksanakan selama 30 hari (D-1 sampai D-30) dengan tujuan untuk mengetahui pengaruh lama penyinaran (fotoperiod) terhadap sintasan dan pertumbuhan larva kerapu tikus. Adapun perlakuan fotoperiod sebagai berikut: 24 jam terang : 0 jam gelap $(24 \mathrm{~L}: 0 \mathrm{D}) ; 18$ jam terang : 6 jam gelap (18 L : 6 D) dan 12 jam terang : 12 jam gelap (12 L : $12 \mathrm{D}$ ). Masing-masing perlakuan diulang tiga kali. Wadah yang digunakan adalah wadah serat kaca silinder bervolume 1000 liter sebanyak 12 buah. Bugian dalam tanki di cat warna abu-abu. Kepadatan awal larva baru menetas adalah 30.000/tank. Pakan alami adalah rotifer (Brachionus rotundiformis) diberikan mulai D-3 dengan kepadatan $20.30 \mathrm{ind} / \mathrm{mL}$, naupli artemia mulai D-15 dengan kepadatan 1 ind/larva dan meningkat hingga 100 ind/larva sesuai dengan peningkatan kebutuhan larva. Kedua jenis pakan ini diberikan hingga D-30 dengan frekuensi 2-3 kali per hari untuk mempertahankan jumlah pakan dalam bak pemeliharaan. Rancangan penelitian adalah rancangan acak kelompok. Hasil yang diperoleh berupa sintasan sebesar 1,40; 2,97 dan $3,92 \%$ serta panjang total larva sebesar 10,$11 ; 11,93 \mathrm{dan} 11,58 \mathrm{~mm}$ berturut-turut pada perlakuan 24 L : 0 D; 18 L: $6 \mathrm{D}$ dan 12 L: $12 \mathrm{D}$. Hasil analisis statistik menunjukkan bahwa fotoperiod berpengaruh terhadap sintasan $(P<0,05)$, namun tidak berbeda nyata terhadap pertumbuhan $(P>0,05)$.
\end{abstract}

\section{ABSTRACT: Larva rearing of polkadots grouper (Cromileptes altivelis) with different} photoperiod. By: Jhon H. Hutapea, Wardoyo and Ketut Maha Setiawati.

Technology on the breeding of polkarlots grouper, Cromileptes altinelis is still not developed, because the limited information on biology and environmental aspects of larvae. To complete the information, some experiments must be done, such as the effect of photoperiod on growth and survival rate of grouper larnae. The experiment was conducted for 30 days $(D-1$ until D-30). The purpose of the experiment was to know the effect of photoperiod on survival rate and growth rate of polkadots grouper larvae. Photoperiod treatment : 24 Light $(L): 0$ Dark $(D), 18 L: 6$ D and 12 $L: 12 \mathrm{D}$. Each treatment was applied in three replicates and arranged in a randomized block design. The experiment uas conducted in 12 circular fiberglass tanks of 1000 litre each. The inner walls of tanks were painted grey. Each tank was stocked with 30.000 newly hatched larvae. Rotifer (Brachionus rotundiformis) of $20.30 \mathrm{ind} . / \mathrm{ml}$ were given to $D .3$ larvae and nauplii of artemia at D. 15 to D.30. Number of artemia given uere gradually increased from 1 to 100 ind./lariae according to the age and size of larvae. The result showed that the survival rate were 1.40, 2.97 and $3.92 \%$ with total length of $10.11,11.93,11.58 \mathrm{~mm}$ for $24 \mathrm{~L}: 0 \mathrm{D}, 18 \mathrm{~L}: 6 \mathrm{D}$ and $12 \mathrm{~L}: 12 \mathrm{D}$ treatment respectively. Statistical analysis showed that the survival rate of larvae was affected significantly by photoperiod $(P<0.05)$ but not the growth rate $(P>0.0 .5)$.

KEYWORDS: Larva rearing, polkadots grouper, photoperiod.

*) Peneliti pada Loka Penelitian Perikanan Pantai Gondol - Bali 


\section{PENDAHULUAN}

Beberapa jenis ikan kerapu merupakan jenis ikan laut yang semakin digemari oleh masyarakat baik domestik maupun internasional antara lain kerapu macan (Epinephelus fuscoguttatus), kerapu sunu (Plectropomus maculatus), kerapu lumpur (Epinephelus suillus) serta kerapu tikus (Cromileptes altivelis). Kebutuhan akan ikan kerapu tersebut, selama ini hanya dapat dipenuhi melalui peningkatan penangkapan dari alam secara bebas. Hal tersebut dapat menyebabkan terjadinya tangkap lebih (over fishing) baik dari segi ukuran maupun jumlah. Untuk mengantisipasi kondisi di atas maka perlu dilakukan upaya budidaya walaupun ketersediaan benih masih menjadi kendala utama.

Kendala dalam upaya perbenihan kerapu adalah terbatasnya informasi dasar karena penelitian mengenai kerapu belum banyak dilakukan. Permasalahan utama dalam pemeliharaan larva kerapu adalah tingginya tingkat kematian pada masa larva, padahal sasaran utama dalam perbenihan adalah meningkatkan sintasan dan pertumbuhan larva, namun tingkat kematian yang tinggi sering terjadi pada saat peralihan sumber nutrisi dari dalam (endogenous) berupa kuning telur (yolk) dan butir minyak (oil globule) ke nutrisi dari luar yang dikenal dengan konsep periode kritis (May, 1974; Hunter, 1976; Imai, 1980). Berdasarkan hasil penelitian Aslianti (1996), dengan pencahayaan alami diperoleh sintasan larva berkisar antara 0,05-1,95\%. Sintasan larva stadia awal dipengaruhi oleh faktor nutrisi, ukuran makanan, kepadatan dan kelengkapan nutrisi pakan dan kondisi pemeliharaan larva termasuk intensitas cahaya optimal, suhu, salinitas, $\mathrm{pH}$ dan oksigen terlarut (Battaglene et al., 1994). Salah satu penyebab tingginya tingkat kematian dalam pemeliharaan awal larva ikan kerapu adalah kegagalan dan keterlambatan larva untuk memulai aktivitas makan dan rendahnya daya pemangsaan larva (Kohno et al., 1990).

Pengaturan cahaya yang tepat sangat penting dalam pemeliharaan larva kerapu (Susanti et al., 1993; Tandler \& Mason, 1982), khususnya periode pencahayaan antara terang dan gelap (Kohno \& Duray, 1988) merupakan faktor lingkungan hidup yang cocok bagi larva untuk meningkatkan aktivitas makan sehingga akan berpengaruh terhadap sintasan larva. Selanjutnya Hunter (1980), menyatakan bahwa larva ikan laut umumnya bersifat "vision feeding" dalam aktivitas pencarian dan pemangsaan pakan. Thorson dalam Nybakken (1988) menyatakan bahwa larva juga tanggap terhadap berbagai faktor fisika-kimia seperti cahaya, tekanan dan salinitas. Selanjutnya dikatakan bahwa sebagian besar larva ikan mengapung bebas dan bersifat fototaksis positif pada stadia awal.

Bertitik tolak pada permasalahan tingginya mortalitas larva kerapu, maka dilakukan penelitian pengaruh tingkat fotoperiod terhadap sintasan dan pertumbuhan larva kerapu.

\section{BAHAN DAN METODE}

Penelitian ini dilaksanakan di laboratorium Loka Penelitian Perikanan Pantai Gondol, Bali selama 30 hari. Sebagai hewan uji adalah larva kerapu tikus (C. altivelis) umur satu hari (D-1) dengan padat tebar awal 30 larva/liter.

Wadah yang digunakan adalah bak serat gelas berbentuk silinder volume 1000 liter sebanyak sembilan buah yang pada awal penebaran diisi air laut sebanyak 700 liter.

Tingkat fotoperiod yang berbeda dijadikan sebagai perlakuan yaitu: 24 jam terang : 0 jam gelap (24 L : $0 \mathrm{D}) ; 18$ jam terang : 6 jam gelap (18 $\mathrm{L}: 6 \mathrm{D})$ dan 12 jam terang : 12 jam gelap $(12 \mathrm{~L}$ : 12 D) pada tingkat intensitas cahaya rendah (300 lux) dengan menggunakan lampu TL yang dihubungkan dengan pengatur waktu otomatis. Pengukuran intensitas cahaya dilakukan $2-3 \mathrm{~cm}$ dari atas permukaan air. Masing-masing perlakuan diulang tiga kali dengan rancangan percobaan adalah rancangan acak kelompok dengan satu perlakuan ditempatkan pada satu ruangan.

Larva umur dua hari dan seterusnya diberi Nannochloropsis sp.dengan kepadatan $1,0 \times 10^{6}$ $\mathrm{sel} / \mathrm{mL}$. Hari ke-3 mulai diberi rotifera (Brachionus rotundiformis) sebagai pakan larva dengan kepadatan 20-30 ind/mL. Untuk mempertahankan kepadatan rotifera dalam bak pemeliharaan larva, dilakukan penghitungan setiap pagi hari. Mulai hari ke-15, larva diberi pakan naupli artemia dengan jumlah satu naupli/larva/hari untuk mengetahui apakah larva sudah dapat makan naupli artemia. Hari berikutnya dihitung 
sisa naupli artemia di bak larva, jika ditemukan naupli artemia dalam bak maka tidak perlu dilakukan penambahan namun jika habis dilaku. kan penambahan sebanyak 5-10 naupli/larva/ hari. Pada hari ke-30 (D-30) larva tersebut dapat memakan naupli artemia sebanyak 100 naupli/ larva/hari dengan frekuensi pemberian pakan $2-3$ kali.

Peubah yang diamati adalah pertumbuhan dan sintasan larva. Untuk pengamatan pertumbuhan yang meliputi panjang total dan panjang standar dilakukan pengambilan larva secara acak setiap lima hari sekali dimulai dari D-1. Dengan menggunakan mikroskop yang dilengkapi mikrometer dilakukan pengukuran larva. Kemudian untuk penghitungan sintasan larva dilakukan pengambilan contoh secara acak pada malam hari dengan menggunakan pipa berdiameter empat inci dilakukan setiap lima hari dan penghitungan seluruh larva pada akhir penelitian. Pengamatan intensitas cahaya serta kualitas air yang meliputi suhu, $\mathrm{pH}$, salinitas dan oksigen terlarut dilakukan setiap hari.

\section{HASIL DAN PEMBAHASAN}

Pengaruh lama penyinaran terhadap sintasan larva kerapu tikus selama 30 hari pemeliharaan disajikan pada Tabel 1 dan Gambar 1.

Tabel 1. Sintasan larva kerapu tikus (C. altivelis) dengan lama penyinaran berbeda selama 30 hari pemeliharaan.

Table 1. Survival rates of polkadots grouper larvae (C. altivelis) with different lengths of photoperiod during 30 days rearing.

\begin{tabular}{lccc}
\hline $\begin{array}{c}\text { Perlakuan } \\
\text { Treatment }\end{array}$ & \begin{tabular}{c} 
Jumlah larva (Number of larvae) (ind.) \\
\cline { 2 - 3 }
\end{tabular} & $\begin{array}{c}\text { Awal (Initial) } \\
\begin{array}{c}\text { Sintasan } \\
\text { Survival rate } \\
\text { (\%) }\end{array}\end{array}$ \\
\hline 24 L : 0 D & 30.000 & 423 & $1.40^{\text {a }}$ \\
18 L : 6 D & 30.000 & 894 & $2.97^{\text {ab }}$ \\
12 L : 12 D & 30.000 & 1.176 & $3.92^{\mathrm{b}}$ \\
\hline * Angka dalam kolom yang diikuti huruf superskrip yang sama menunjukkan tidak berbeda nyata (P>0,05) \\
* Values in column with the same superscript indicated not significantly different $(P>0.05)$
\end{tabular}

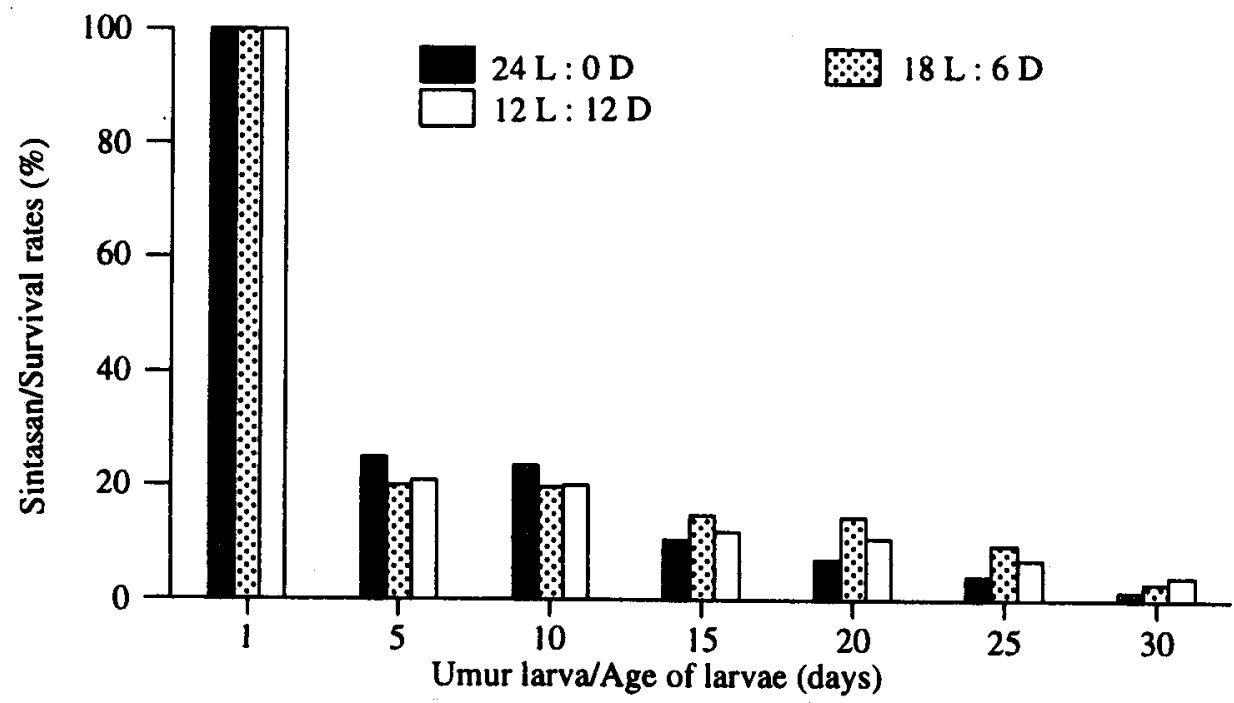

Gambar 1. Grafik hubungan antara umur dengan sintasan larva kerapu tikus (C. altivelis) pada lama penyinaran berbeda.

Figure 1. Age and survival rate relationship of polkadots grouper larvae (C. altivelis) at different lengths of photoperiod. 
Hasil analisis statistik menunjukkan bahwa sintasan larva kerapu tikus pada akhir penelitian perlakuan fotoperiod $18 \mathrm{~L}: 6 \mathrm{D}$ tidak berbeda dengan perlakuan $24 \mathrm{~L}: 0 \mathrm{D}$ dan $12 \mathrm{~L}: 12 \mathrm{D}$, sedangkan sintasan pada perlakuan photoperiod $24 \mathrm{~L}$ : $0 \mathrm{D}$ lebih rendah dibandingkan perlakuan $12 \mathrm{~L}$ : $12 \mathrm{D}(\mathrm{P}<0,05)$. Dari hasil ini terlihat bahwa periode gelap (antara 6-12 jam) diperlukan untuk kehidupan larva.

Battaglene \& Talbot (1990), menyatakan bahwa larva ikan Australian bass (Macquaria novemaculata) dengan penurunan intensitas cahaya yang dikombinasikan dengan lama periode gelap terang yang sama cenderung meningkat kan sintasan larva serta dapat meningkatkan fungsi gelembung renang (swim bladder inflant ion). Umumnya masa kritis pada berbagai jenis larva ikan air laut selalu dihubungkan antara faktor cahaya, fotoperiod dan salinitas dengan tingkat keberhasilan fungsi gelembung renang. Anonymous (1987), mengemukakan bahwa larva ikan kakap mencapai fungsi gelembung renang maksimum dalam tangki warna gelap dengan intensitas cahaya yang rendah. Bahkan umumnya Australian bass pada stadia awal dipelihara dalam lingkungan pemeliharaan yang gelap. Namun menurut Fernandes (1979) untuk pemeliharaan larva secara intensif banyak digunakan pencahayaan yang terus-menerus. Selanjutnya
Fernandes (1979) serta Tandler \& Helps dalam Battaglene et al., (1994), menyatakan bahwa pencahayaan yang terus-menerus dapat mempercepat pertumbuhan selama pemeliharaan larva namun sering juga ditemui tingkat kematian yang tinggi.

Hasil pengamatan pertumbuhan panjang total dan panjang standar larva disajikan pada Tabel 2 dan Gambar 2. Berdasarkan Gambar 2, fotoperiod tidak berpengaruh terhadap pertumbuhan larva.

Hasil analisis statistik menunjukkan bahwa pertumbuhan larva kerapu tikus pada akhir penelitian pada semua perlakuan fotoperiod tidak berbeda nyata $(P>0,05)$.

Berdasarkan hasil pengamatan, aktivitas gerak larva tetap mengikuti pola fotoperiod alami yaitu siang aktif dan malam pasif walaupun diberi cahaya lampu yang kurang terang (105-270 lux). Hal tersebut juga dialami pada larva Sillago ciliata Cuvier, yaitu pada malam hari menyebar lebih merata pada bak pemeliharaan dan cenderung melayang-layang daripada mencari makanan (Battaglene et al., 1994).

Hasil pengamatan kualitas air, secara umum masih layak untuk kehidupan larva ikan (Tabel 3). Keadaan tersebut dapat dikontrol dengan sistem pergantian air yang teratur.

Tabel 2. Panjang total dan panjang standar larva kerapu tikus (C. altivelis) dengan lama penyinaran yang berbeda selama 30 hari pemeliharaan.

Table 2. Total and standard length of polkadots grouper larvae (C. altivelis) with different lengths of photoperiod during 30 days rearing.

\begin{tabular}{ccccc}
\hline \multirow{2}{*}{$\begin{array}{c}\text { Perlakuan } \\
\text { Treatment }\end{array}$} & \multicolumn{4}{c}{ Panjang larva (Length of larvae) (mm) } \\
\cline { 2 - 5 } & \multicolumn{2}{c}{ Awal (Initial) } & \multicolumn{2}{c}{ Akhir (Final) } \\
\cline { 2 - 5 } & PT & PS & PT & PS \\
\hline 24 L: 0 D & 2.37 & 2.26 & $10.11^{\mathrm{a}}$ & 8.32 \\
18 L: 6 D & 2.37 & 2.26 & $11.93^{\mathrm{a}}$ & 9.89 \\
12 L: 12 D & 2.37 & 2.26 & $11.58^{\mathrm{a}}$ & 9.73 \\
\hline
\end{tabular}

PT : Panjang total larva (Total length of larvae)

PS : Panjang standar larva (Notocord/standard length of larvae)

* Nilai dalam kolom diikuti dengan huruf yang sama tidak berbeda nyata $(P>0,05)$ Averages in columns with the same superscript are not significantly different $(P>0.05)$ 


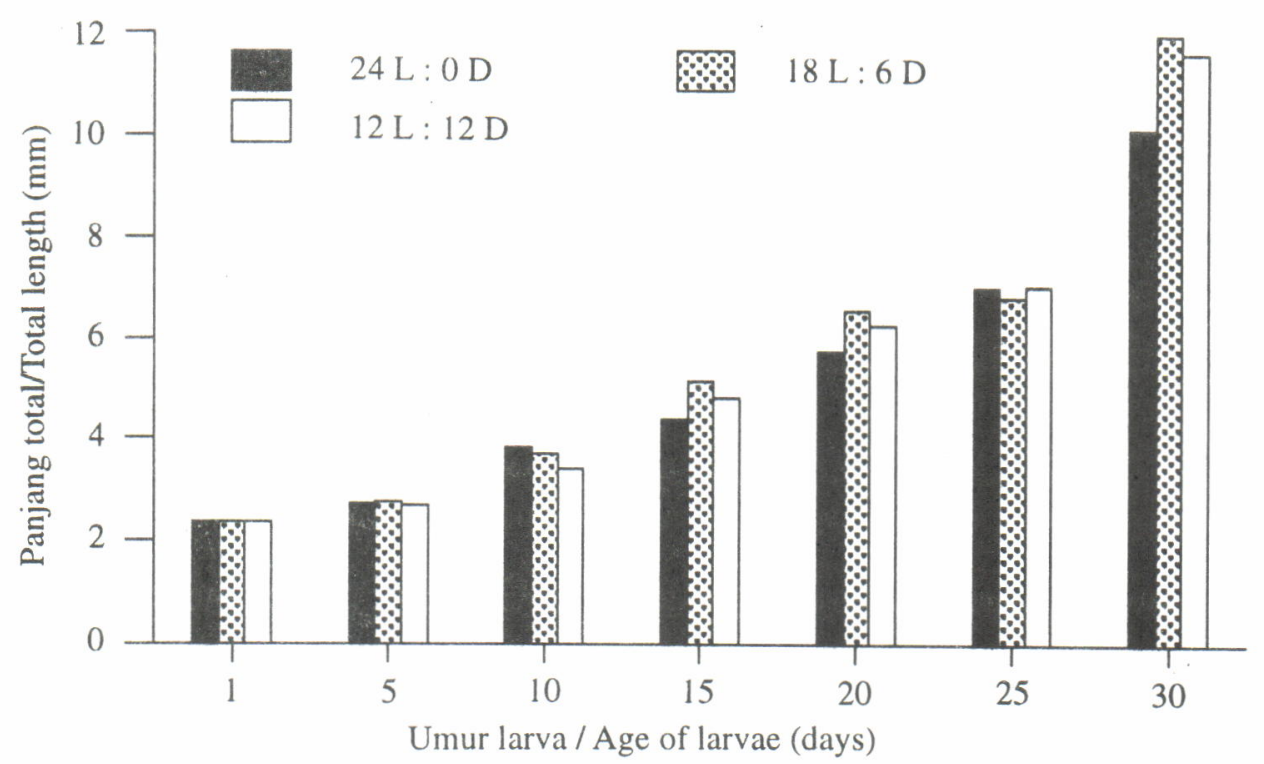

Gambar 2. Grafik hubungan antara umur dan panjang total larva kerapu tikus (C. altivelis) pada lama penyinaran berbeda.

Figure 2. Age and total length relationship of polkadots grouper larvae (C. altivelis) at different lengths of photoperiod.

Tabel 3. Nilai rata-rata kualitas air dan intensitas selama 30 hari pemeliharaan larva.

Table 3. Mean values of water quality and light intensity during 30 days rearing.

\begin{tabular}{cccccc}
\hline $\begin{array}{c}\text { Perlakuan } \\
\text { Treatment }\end{array}$ & $\begin{array}{c}\text { Suhu } \\
\text { Temperature } \\
\left({ }^{\circ} \mathbf{C}\right)\end{array}$ & pH & $\begin{array}{c}\text { Salinitas } \\
\text { Salinity } \\
\text { (ppt) }\end{array}$ & DO & $\begin{array}{c}\text { Int. cahaya } \\
\text { Light intensity } \\
(\mathbf{p p m})\end{array}$ \\
\hline 24 L : 0 D & 27.5 & 7.58 & 32 & 4.00 & $105-270$ \\
18 L : 6 D & 27.7 & 7.50 & 32 & 4.00 & $131-254$ \\
12 L : 12 D & 27.9 & 7.56 & 32 & 4.00 & $165-267$ \\
\hline
\end{tabular}

\section{KESIMPULAN}

Lama periode gelap (antara 6-12 jam) diperlukan untuk meningkatkan sintasan larva kerapu tikus (C. altivelis).

Tingkat fotoperiod yang berbeda tidak berpengaruh terhadap pertumbuhan larva kerapu bebek.

\section{DAFTAR PUSTAKA}

Anonymous. 1987. Bass and bream go commercial. Fish Farmer 10 (5):30-32.

Aslianti, T. 1996. Pemeliharaan larva kerapu bebek Cromileptes altivelis dengan padat tebar telur berbeda. J. Penel. Perikanan Indonesia II (2) :6-12.
Baharona-Fernandes, M.H. 1979. Some effects of light intensity and photoperiod on the sea bass larvae (Dicentrarchus labrax L.) reared at the Centre Oceanologique de Bretagne. Aquaculture 17:311. 321.

Battaglene, S.C. and R.B. Talbot. 1990. Initial swim bladder inflantion in intensively reared Australian bass larvae, Macquaria novemaculata (Steindachner) (Perciformes: Percichthyidae). Aquaculture 86:431-442.

Battaglene, S.C., S. McBride and R.B. Talbot. 1994. Swim bladder inflantion in larvae of cultured sand whiting, Sillago ciliata Cuvier (Sillaginidae). Aquaculture 128:177-192.

Hunter, J.R. 1976. Report on the colloquium on larval fish mortality studies and their relation to fishery 
research, January 1975. Natl. Ocean. Atmos. admin. Techh. Rep. Natl. Mar. Fish. Serv. Circ. 395:1-5.

Hunter, J.R. 1980. The feeding behavior and ecology of fish larval. In Bardach, E., J. Magnuson, R.C. May, J.M. Reinhart (Eds.). Fish behavior and its use in the capture of fishes. ICLARM. Conference Proceeding (5):512 p.

Imai, T. 1980. Sensory anatomy and feeding of fish larvae. In J.E. Bardach, J.J. Magnuson, R.C. May and J.M. Reinhart (Editors). Fish behaviour and its use in the capture and culture of fishes. ICLRAM Conference Proceedings 5, International Centre for the Living Aquatic Recources Management, Manila.

Kohno, H. and M. Duray. 1988. Effect of continuous lighting of growth and survival of fish feeding larvae rabbit fish. Siganus guttatus. Aquaculture (72):72-79.

Kohno, H., S. Diani, P. Sanyoto, B. Slamet and P.T. Imanto. 1990. Early developmental events associated with change over of nutrient sources in the grouper, Epinephelus fuscoguttatus larvae. Bull. Penel. Perikanan, special edition (1):41-46.

May, R.C. 1974. Larval mortality in marine fishes and critical period concept. In J.H.S. Blaxter (Editor) The Early Life History of Fish Springer-Verlag, Berlin

Nybakken, J.W. 1988. Marine biology. An ecological approach. Second edition. Harper Collins Publisher. 541 p.

Susanti, D., P.T. Imanto dan D. Yosiva. 1993. Pengaruh berbagai periode waktu pemberian cahaya (photoperiod) terhadap pertumbuhan dan kelangsungan hidup larva ikan kakap putih, Lates calcarifer. J. Penel. Budidaya Pantai 9(5):137-145.

Tandler, A. and C. Mason. 1982. Light and food density effects on growth and survival of larva gilthead seabream (Sparus auratus, Linnaeus, Sparidae). J. World Mariculture Sco. (14):103-109. 


\title{
PEMATANGAN INDUK KERAPU BEBEK (Cromileptes altivelis) DENGAN RANGSANGAN SUNTIKAN HORMON LHRHa DAN 17- $\alpha$ METHYLTESTOSTERON
}

\author{
Tridjoko*), Bejo Slamet ${ }^{*}$ dan Dahlan Makatutu*)
}

\begin{abstract}
ABS'TRAK
Penelitian ini bertujuan untuk mengetahui jenis hormon yang tepat dalam menunjang tingkat kematangan gonad ikan kerapu bebek Cromileptes altivelis. Individu yang digunakan adalah ikan kerapu bebek dengan kisaran bobot antara 1,1-2,7 kg/ekor dengan panjang total antara 42,0 - 57,0 $\mathrm{cm}$. Bak yang digunakan adalah bak serat gelas dengan ukuran volume $5 \mathrm{~m}^{3}$ sebanyak empat buah masing-masing diisi lima ekor induk kerapu bebek. Sebagai perlakuan adalah suntikan: hormon LHRH-a, hormon 17- $\alpha$ methyltestosteron, kombinasi 50\% hormon LHRH-a dan $50 \%$ hormon 17- $\alpha$ methyltestosteron, dan kontrol (tanpa diberi hormon).
\end{abstract}

Hasil menunjukkan bahwa induk kerapu bebek yang disuntik dengan hormon LHRH-a dan hormon 17- $\alpha$ mehtyltestosteron dengan dosis $50 \mu \mathrm{g} / \mathrm{kg}$ bobot ikan mampu menghasilkan telur dengan diameter lebih dari400 $\mu \mathrm{m}$ yang siap memijah.

\section{ABSTRACT: Maturation on polka dots grouper (Cromileptes altivelis) induced by hormone injection LHRH-a and $17 \alpha$ methyltestosteron. By: Tridjoko, Bejo Slamet and Dahlan Makatutu.}

The purpose of the study was to know the effective dosage and type of hormone to stimulate the gonad development of grouper Cromileptes altivelis. The grouper spawners weighing 1.1-2.7 $\mathrm{kg} / \mathrm{pcs}$, total length $42.0-57.0 \mathrm{~cm}$ were reared in 4 fibre glass tanks of $5 \mathrm{~m} 3$ capacity each with stocking density of 5 fish per tank. Dosages of hormon, i.e $50 \mu \mathrm{g} \mathrm{LHRH-a/kg} \mathrm{fish,} 50 \mu \mathrm{g} \mathrm{17 \cdot \alpha}$ methyltestosteron and 50\% LHRH-a and 50\% 17- $\alpha$ methyltestosteron in combination were applied as treatments.

The result of the study showed that spawners injected with LHRH-a and 17-a methyltestosteron $50 \mu \mathrm{g} / \mathrm{kg}$ fish bodyweight could induce the gonad development. Diameter of eggs had developed to be more than $400 \mu \mathrm{m}$ and all the fish were succesfully spawned.

\section{KEYWORDS: hormon injection, grouper, gonad development.}

\section{PENDAHULUAN}

Ikan kerapu dapat memijah secara alami, buatan dan pijah rangsang. Pada dasarnya ada tiga cara untuk memacu perkembangan gonad, yaitu dengan manipulasi lingkungan, pakan dan hormonal. Banyak jenis hormon yang dapat digunakan untuk merangsang perkembangan gonad, namun masing-masing jenis hormon mempunyai dosis yang berbeda untuk injeksi ikan sehingga mampu mempercepat tingkat kematangan gonad (Chen et al., 1977; Vanstone et al., 1977).

Secara alami perkembangbiakan banyak tergantung pada kesiapan induk yang matang telur dan biasanya hanya terjadi pada musim-musim tertentu saja. Usaha perkembangbiakan secara buatan dengan manipulasi hormonal dapat di- lakukan dengan cara penyuntikan LHRH-a, 17- $\alpha$ methyltestosteron dan HCG (Vanstone et al., 1977; Lee et al., 1986; Kuo et al., 1988). Hormon LHRH-a dosis $100 \mu \mathrm{g}$ dapat memacu pematangan gonad ikan bandeng (Prijono et al., 1993). Bertitik tolak pada permasalahan tersebut, penelitian ini bertujuan untuk mengetahui jenis dan dosis hormon yang tepat dalam memacu tingkat kematangan gonad ikan kerapu bebek (Cromileptes altivelis).

\section{BAHAN DAN METODE}

Percobaan ini dilakukan di Loka Penelitian Perikanan Pantai Gondol Bali selama 4,5 bulan yaitu dari bulan Oktober 1995 sampai Februari 1996. Individu yang digunakan dalam penelitian ini adalah ikan kerapu bebek (C. altivelis) dengan kisaran bobot antara 1,1-2,7 kg/ekor dengan

\footnotetext{
*) Peneliti pada Loka Penelitian Perikanan Pantai Gondol - Bali
} 
panjang total antara $42,0-57,0 \mathrm{~cm} / \mathrm{ekor}$. Bak beton volume 20 ton digunakan untuk aklimatisasi, kemudian ikan dipindahkan ke dalam bak serat gelas volume lima ton sebanyak empat buah yang diisi lima ekor kerapu bebek belum matang gonad pada masing-masing bak. Induk ikan yang belum matang gonad dapat dilihat dengan cara kanulasi yaitu memasukkan pipa plastik kecil diameter $1 \mathrm{~mm}$ ke dalam saluran pelepasan telur, kemudian disedot dan dilihat di bawah mikroskop dan ternyata tidak ada telurnya (kosong). Pada bak pemeliharaan dilengkapi aerasi dan pergantian air sebanyak $300 \%$ /hari dengan sistem air mengalir.

Hormon yang digunakan adalah $\mathrm{LHRH}-\mathrm{a}$ dan 17- $\alpha$ methyltestosteron yang berupa serbuk, kemudian masing-masing diambil $1 \mathrm{mg}$ dan ditambahkan aquabidest $5 \mathrm{~mL}$ sehingga berupa larutan supaya didapatkan $200 \mu \mathrm{g}$ setara dengan 1 cc. Sebagai perlakuan adalah penyuntikan hormon berupa larutan yang sudah disetarakan dengan dosis $50 \mu \mathrm{g}$ sebagai berikut: (1) Hormon LHRH-a; (2) Hormon 17- $\alpha$ methyltestosteron; (3) Kombinasi $50 \%$ hormon LHRH-a dan 50\% hormon 17- $\alpha$ methyltestosteron; (4) Kontrol (tidak disuntik hormon). Hormon tersebut disuntikkan secara intramuskular di bawah sirip dorsal (soft dorsal fin) dengan dosis $50 \mu \mathrm{g} / \mathrm{kg}$ bobot badan dan disuntikkan setiap bulan sekali.

Selama pemeliharaan induk diberi pakan berupa ikan rucah dan cumi-cumi sebanyak $3-5 \%$ biomassa per hari yang ditambahkan vitamin $\mathrm{C}$ dan $\mathrm{B}$ kompleks dengan dosis $0,5 \mathrm{mg} / \mathrm{kg}$ bobot ikan. Penambahan vitamin $\mathrm{C}$ dan B kompleks adalah berupa tablet yang dimasukkan ke dalam ikan rucah atau cumi-cumi yang telah dipotong yang diberikan setiap tiga hari sekali. Pengamatan tingkat kematangan gonad berdasarkan perkembangan atau ukuran telur (oocyts) dilakukan setiap bulan dengan cara membius dan melakukan kanulasi pada saluran pelepasan telur kemudian disedot perlahan-lahan untuk mengetahui ada tidaknya sel telur atau sperma. Hasil dari kanulasi dilihat di bawah mikroskop yang dilengkapi dengan mikrometer untuk mengetahui diameter telur atau keragaan sperma. Induk ikan disadarkan kembali dengan cara melepaskan ikan tersebut pada media air yang segar, selanjutnya dilepas kembali ke dalam masing. masing bak pemeliharaan semula. Pengamatan kualitas air dilakukan setiap dua minggu sekali yang meliputi: suhu, salinitas, $\mathrm{pH}$, nitrit, nitrat, fosfat dan amonia. Data dianalisis secara diskriptif.

\section{HASIL DAN PEMBAHASAN}

Hasil pengamatan terhadap persentase perkembangan telur dalam gonad ikan kerapu bebek (C. altivelis) setiap individu pada masing-masing perlakuan dan waktu pengamatan dapat dilihat pada Tabel 1. Dari Tabel 1 terlihat bahwa hasil pengamatan perkembangan gonad induk kerapu bebek menunjukkan ada peningkatan setiap bulannya. Pada awal percobaan (Oktober 1995) semua perlakuan 100\% dalam keadaan PV (previtelogenetic) yang ditunjukkan adanya calon sel telur atau kosong. Sampai dengan bulan Februari 1996 terdapat jantan +2 sebanyak $20 \%$ dan betina $40 \%$ dengan diameter telur $>400 \mu \mathrm{m}$. Pada perlakuan hormon 17- $\alpha$ methyltestosteron, sampai dengan bulan Februari 1996 tidak ditemukan induk jantan yang matang, sedang yang betina diameter $>400 \mu \mathrm{m}$ sebesar $20 \%$. Perlakuan campuran hormon 50\% LHRH-a 50\% 17- $\alpha$ methyltestosteron, menunjukkan bahwa sampai dengan bulan Februari terdapat induk jantan yang matang gonad +2 sebesar $20 \%$ dan betina diameter telur antara $301-400 \mu \mathrm{m}$ sebesar $20 \%$. Sedangkan untuk kontrol (tanpa disuntik hormon) hingga bulan Februari 1996 tidak ditemukan induk yang jantan dan yang betina $60 \%$ diameter telur $<100 \mu \mathrm{m}, 20 \%$ diameter telur antara $101-200 \mu \mathrm{m}$ dan $20 \%$ diameter telur antara 201-300 $\mu \mathrm{m}$. Dengan demikian induk kerapu bebek yang disuntik dengan hormon memperlihatkan adanya perkembangan gonad yang lebih cepat dibandingkan dengan yang tidak disuntik (kontrol).

Di dalam proses reproduksi, sebelum terjadi pemijahan sebagian besar hasil metabolisme bertujuan untuk perkembangan gonad. Bobot gonad bertambah sejalan dengan meningkatnya diameter telur, di mana bobot maksimum dicapai saat ikan memijah, kemudian bobot gonad akan menurun dengan cepat selama pemijahan berlangsung sampai selesai (Effendie, 1979; Mayunar, 1992). Secara alami perkembangbiakan ikan banyak tergantung dari kesiapan induk yang matang telur dan hal ini biasanya hanya terjadi pada musim-musim tertentu. Hasil penangkapan ikan para nelayan ternyata ikan 
Tabel 1. Perkembangan tingkat kematangan gonad selama percobaan (\%).

Table 1. Gonad development stage during experiment (\%).

\begin{tabular}{|c|c|c|c|c|c|c|c|}
\hline $\begin{array}{l}\text { Perlakuan } \\
\text { Treatment }\end{array}$ & $\begin{array}{c}\text { Diameter telur } \\
\text { Egg Diameter } q \\
(\mu \mathrm{m})\end{array}$ & $\begin{array}{c}\text { Tingkatan } \\
\text { sperma } \\
\text { Stage of } \\
\text { Sperm } \\
\end{array}$ & $\begin{array}{l}\text { Okt. } \\
\text { Oct. }\end{array}$ & $\begin{array}{l}\text { Nov. } \\
\text { Nov. }\end{array}$ & $\begin{array}{l}\text { Des. } \\
\text { Dec. }\end{array}$ & $\begin{array}{l}\text { Jan. } \\
\text { Jan. }\end{array}$ & $\begin{array}{l}\text { Feb. } \\
\text { Feb. }\end{array}$ \\
\hline \multirow{8}{*}{ LHRH-a } & $<100$ & & 100 & 60 & 40 & - & - \\
\hline & $101 \cdot 200$ & & & - & 20 & 20 & 20 \\
\hline & $201-300$ & & - & 20 & 20 & 20 & 20 \\
\hline & $301-400$ & & - & $\cdot$ & $\cdot$ & 20 & - \\
\hline & $>400$ & & . & - & - & 20 & 40 \\
\hline & & + & - & 20 & $\cdot$ & - & - \\
\hline & & ++ & - & & 20 & 20 & 20 \\
\hline & & +++ & - & - & . & - & - \\
\hline \multirow{8}{*}{ 17- $\alpha \mathrm{MT}$} & $<100$ & & 100 & 80 & 80 & 20 & - \\
\hline & $101 \cdot 200$ & & & 20 & & 20 & 20 \\
\hline & $201 \cdot 300$ & & - & - & 20 & 40 & 20 \\
\hline & $301-400$ & & & & - & 20 & 40 \\
\hline & $>400$ & & - & & - & - & 20 \\
\hline & & + & - & - & - & - & - \\
\hline & & ++ & & - & - & - & \\
\hline & & +++ & - & - & - & - & - \\
\hline \multirow{8}{*}{$\begin{array}{c}\text { Kombinasi } \\
\text { Combination }\end{array}$} & $<100$ & & 100 & 60 & 60 & 20 & 20 \\
\hline & $101-200$ & & - & 20 & 20 & 40 & 40 \\
\hline & $201-300$ & & & & & 20 & 20 \\
\hline & $301-400$ & & & & - & - & - \\
\hline & $>400$ & & - & - & - & - & - \\
\hline & & + & - & 20 & - & - & - \\
\hline & & ++ & & - & 20 & 20 & 20 \\
\hline & & +++ & - & - & - & . & - \\
\hline \multirow{8}{*}{$\begin{array}{l}\text { Kontrol } \\
\text { Control }\end{array}$} & $<100$ & & 100 & 80 & 80 & 60 & 60 \\
\hline & $101-200$ & & - & 20 & - & 20 & 20 \\
\hline & $201-300$ & & & - & 20 & 20 & 20 \\
\hline & $301-400$ & & - & & - & - & - \\
\hline & $>400$ & & & - & - & - & \\
\hline & & + & & & & & - \\
\hline & & ++ & - & - & - & - & - \\
\hline & & +++ & - & - & - & - & - \\
\hline
\end{tabular}

kerapu bebek sulit didapatkan yang matang telur. Dengan pengalaman yang demikian usaha mematangkan gonad secara buatan sangatlah penting. Dan ternyata dengan penyuntikan hormon LHRH-a dan 17- $\alpha$ methyltestosteron dapat memacu perkembangan gonad ikan kerapu bebek. Jenis hormon tersebut telah berhasil mem- percepat perkembangan gonad dan pemijahan pada beberapa spesies ikan, seperti halnya juga pada ikan bandeng (Vanstone et al., 1977; Lee et al., 1986; Kuo et al., 1988) dan ikan Nassau grouper Epinephelus striatus (Watanabe et al., 1995). Keberhasilan ini telah dibuktikan pada implantasi kristal hormon 17-œ methyltestosteron 
untuk pemijahan ikan bandeng dengan bobot antara $3,7-5,5 \mathrm{~kg}$ dan berhasil dengan baik (Prijono et al., 1993).

Hasil penelitian Weber \& Lee (1985) menyatakan, hormon 17- $\alpha$ methyltestosteron berpengaruh baik pada androgen yang menghasilkan sperma pada ikan belanak, stickleback dan fundulus. Telah dibuktikan juga secara histologis bahwa 17 . $\alpha$ methyltestosteron dapat memperbaiki sistem perkembangan testis pada ikan. Hormon 17- $\alpha$ methyltestosteron dalam gonad induk ikan adalah untuk mengaktifkan vitelogenesis dan berfungsi untuk menyiapkan kesempurnaan kuning telur (Marte et al., 1980) dan diduga berfungsi timbal balik secara aktif dalam kelenjar hipofisis atau otak. Oleh karena itu, hormon tersebut dapat memperbaiki fungsi utama kelenjar hipopisis untuk membentuk gonadotropin di dalam tahapan perkembangan gonad (Tamaru et al., 1988). Penggunaan hormon untuk proses pematangan gonad, efektif apabila digunakan bertepatan pada saat musim pemijahan di alam (Tamaru et al., 1987). Demikian juga hasil penelitian Crim et al. dalam Tamaru (1990) menyimpulkan bahwa organ yang berperan untuk proses pematangan gonad pada ikan dipengaruhi oleh adanya perubahan musim dan hormonal.

Beberapa tolok ukur peubah kualitas air seperti: suhu, salinitas, oksigen, $\mathrm{pH}$, fosfat, nitrit, nitrat dan amonia berada pada kisaran yang optimal dalam menunjang perkembangan gonad ikan kerapu bebek (Tabel 2).

Tabel 2. Kisaran parameter kualitas air selama penelitian.

Table 2. Range of variables of water quality during the experiment.

\begin{tabular}{lccccc}
\hline \multirow{2}{*}{$\begin{array}{c}\text { Variabel } \\
\text { Variables }\end{array}$} & & \multicolumn{4}{c}{ Perlakuan (Treatment) } \\
\cline { 3 - 6 } & & I & II & III & IV \\
\hline Suhu (Temp.) & $\left({ }^{\circ} \mathrm{C}\right)$ & $28.0-30.5$ & $28.1-30.4$ & $28.0-30.4$ & $28.1-30.5$ \\
Salinitas (Salinity) & $(\mathrm{ppt})$ & $32.0-34.0$ & $32.0-34.0$ & $32.0-34.0$ & $32.0-34.0$ \\
$\mathrm{pH}$ & & $8.00-8.32$ & $8.00-8.31$ & $8.00-8.43$ & $8.00-8.28$ \\
DO & $(\mathrm{ppm})$ & $7.02-7.54$ & $7.00-7.50$ & $7.00-7.49$ & $7.01-7.50$ \\
Fosfat (Phosphate) & $(\mathrm{ppm})$ & $0.027-0.550$ & $0.025-0.540$ & $0.022-0.500$ & $0.027-0.540$ \\
Nitrit (Nitrite) & $(\mathrm{ppm})$ & $0.010-0.043$ & $0.010-0.042$ & $0.010-0.043$ & $0.011-0.045$ \\
Nitrat (Nitrate) & $(\mathrm{ppm})$ & $0.038-0.114$ & $0.035-0.117$ & $0.034-0.119$ & $0.034-0.120$ \\
Amonia (Ammonia) & $(\mathrm{ppm})$ & $0.031-0.051$ & $0.030-0.050$ & $0.032-0.051$ & $0.030-0.051$ \\
\hline
\end{tabular}




\section{KESIMPULAN}

Hormon LHRH-a dan 17- $\alpha$ methyltestosteron dosis $50 \mu \mathrm{g} / \mathrm{kg}$ bobot ikan, cukup baik dalam menunjang perkembangan gonad induk kerapu bebek betina dan mampu menghasilkan telur dengan diameter $>400 \mu \mathrm{m}$ yang siap memijah.

\section{DAFTAR PUSTAKA}

Chen, F.Y., M.Chow., T.M.Chao and R.Lim. 1977. Artificial spawning and larval rearing of the grouper, Ephinephelus tauvina (Forskal) in Singapore, Singapore J. Pri. Ind. 5(1):1-21

Effendi, M.I. 1979. Metode biologi perikanan. Cetakan pertama. Penerbit Yayasan Dewi Sri Cikurai Bogor: $112 \mathrm{p}$.

Kuo, C.M., Y.Y. Ting and S.L.Yeh. 1988. Induced sex reversal and spawning of blue-spotted grouper, Epinephelus fario. Aquaculture 74: 113-126

Lee, C.S., C.S. Tamaru, and C.D. Kelly. 1986. Technique for making chronic release LHRH-a and 17-alpha methyltestosteron pellet for intramuscular implantation in fishes. Aquaculture 59:161-168.

Marte, C.L., L.W Crim and N.M Sherwood. 1980. Induced gonadal maturation and rematuration in milkfish limited succes with chronic administration of testosterone and gonadothropin releasing hormon analogue (GnRha). Aquaculture 74:131146.

Mayunar. 1992. Pijah rangsang dan pemeliharaan larva kerapu lumpur, Epinephelus tauvina. Oceana, Vol; XVII, Nomor 2:69-82.

Prijono, A., G.Sumiarsa dan Z.I. Azwar. 1993. Uji coba implantasi kristal hormon 17 -alpha methyltestos- teron untuk pemijahan induk bandeng, Chanos chanos Forskal 9(1):37-42

Tamaru, C.S., C.S. Lee., C.D. Kelly, and J.E. Banno. 1987. Effectiviness of chronic LHRH-a and 17-alpha methyltestosteron, therapy, administered at different times prior to the spwaning season, on the maturation of milkfish (Chanos chanos), A Thesis Submitted the Graduate Division of the University of Tokyo, Faculty of Agriculture, 40-44 p.

Tamaru, C.S., C.S.Lee, C.D. Kelly, J.E. Banno, P.Y. Ha, K. Aida, and I. Hanyu. 1988. Characterizing the stage of maturity most receptive to an acute LHRH-a therapy for inducing milkfish (Chanos chanos) to spawn, Aqua-culture 74:147-163

Tamaru, C.S. 1990. Studies on the use of chronic and acute LHRH-a treatments on controlling maturation and spawning in the milkfish (Chanos chanos Forsskal) In A Thesis Submitted to the Graduate Division of the University of Tokyo, Faculty of Agriculture 40-44 p

Vanstone, W.E., L.B. Tiro, Jr.A.C.Villaluz, D.C. Barnes and C.E. Duenas. 1977. Breeding and larval rearing of milkfish Chanos chanos (Pisces: Chanidae). SEAFDEC Aquaculture Department Tech. Report 3:3-17

Watanabe,W.O., Simon, C.E., Eileen, P.E., William, O.H., Christopher, D.K., Aaron, M., Cheng, S.L., and Paul, K.B. 1995. Progress in controlled breeding of Nassau grouper Epinephelus striatus broodstock by hormone induction. Aquaculture 138:205-219.

Weber, G.M., and C.S. Lee. 1985. Effect of 17-alpha methyltestosteron on spermatogenesis and Spermation in the grey mullet, Mugil cephalus, Journal Fish Biology 26:77-84. 